Société d'histoire de la révolution de 1848 et des

révolutions du XIXe siècle

$46 \mid 2013$

L'espace du politique en Allemagne au XIX' ${ }^{\mathrm{e}}$ siècle

\title{
Aurélien Lignereux, Servir Napoléon. Policiers et gendarmes dans les départements annexés (1796-1814)
} Seyssel, Champ Vallon, 2012, 395 p. ISBN : 978-2-87673-624-5. 28 euros

Natalie Petiteau

\section{(2) OpenEdition}

Journals

Édition électronique

URL : http://journals.openedition.org/rh19/4461

DOI : 10.4000/rh19.4461

ISSN : $1777-5329$

Éditeur

La Société de 1848

\section{Édition imprimée}

Date de publication : 1 juin 2013

Pagination : 195-196

ISSN : 1265-1354

\section{Référence électronique}

Natalie Petiteau, «Aurélien Lignereux, Servir Napoléon. Policiers et gendarmes dans les départements annexés (1796-1814) », Revue d'histoire du XIXe siècle [En ligne], 46 | 2013, mis en ligne le 13 janvier 2014, consulté le 22 septembre 2020. URL : http://journals.openedition.org/rh19/4461 ; DOI : https:// doi.org/10.4000/rh19.4461

Ce document a été généré automatiquement le 22 septembre 2020.

Tous droits réservés 


\title{
Aurélien Lignereux, Servir Napoléon. Policiers et gendarmes dans les départements annexés (1796-1814)
}

Seyssel, Champ Vallon, 2012, 395 p. ISBN : 978-2-87673-624-5. 28 euros

\author{
Natalie Petiteau
}

\section{RÉFÉRENCE}

Aurélien Lignereux, Servir Napoléon. Policiers et gendarmes dans les départements annexés (1796-1814), Seyssel, Champ Vallon, 2012, 395 p. ISBN : 978-2-87673-624-5. 28 euros.

1 Aurélien Lignereux poursuit ici l'œuvre entreprise avec La France rébellionnaire ${ }^{1}$ en se proposant d'utiliser le prisme des forces de maintien de l'ordre pour observer l'état des esprits dans l'Empire. Mais il s'agit cette fois d'appréhender l'espace étranger de l'Empire de Napoléon, en étudiant les départements annexés. De surcroît, l'auteur ne se contente pas ici d'examiner le rapport des habitants aux agents du maintien de l'ordre : son ambition est de montrer ce qu'est la réalité d'un Empire français de 130 départements, en analysant ce que signifie servir dans ces espaces lorsque l'on est originaire des départements français, ou bien ce que signifie être au service de la France quand on est originaire de ces espaces nouvellement français. En fait, il s'agit d'appliquer à l'Empire napoléonien les problématiques des colonial studies afin de faire avancer nos connaissances sur les réalités sociales et culturelles au sein de cette entité politique spécifique. Il s'agit donc d'une histoire de l'Empire "par en bas», en regardant non plus la tête du pouvoir, mais ses agents dans leurs activités, leurs carrières et leurs trajectoires sociales. Beau projet, qui vient préciser ce que l'auteur n'a pu qu'esquisser dans sa récente synthèse sur la période ${ }^{2}$, et qui s'inscrit dans la lignée des travaux de Jean-Noël Luc, Michael Broers et Catherine Denys, et plus largement d'une histoire européenne des forces de maintien de l'ordre actuellement en plein essor. 
2 Le travail est imposant et habilement construit. Une première partie intitulée «Bâtir l'Empire » montre le processus d'implantation des institutions policières françaises et les voies d'adaptation du dispositif français. Elle souligne la diversité des situations entre les départements où l'entrée en service d'une gendarmerie française a devancé l'annexion et ceux où l'installation des gendarmes suit l'annexion. Elle montre comment se mêlent gendarmes français et autochtones. Les procédures d'implantation se rodent donc au fil des agrandissements, sans qu'existe un système prédéfini et avec une volonté de s'adapter aux contraintes locales. Mais partout, la surveillance des villes est privilégiée.

3 Une deuxième partie, sous le titre "Vivre l'Empire", analyse les politiques de recrutement, les carrières et la vie privée de ces hommes publics. Gendarmes et policiers sont à la fois les produits et les représentants et acteurs de l'Empire. Aurélien Lignereux tente de donner un visage à ces corps; il a constitué pour cela un corpus de plus de 7500 gendarmes et de 620 commissaires de police, afin de repérer entre autres la part des recrutements autochtones, jamais négligeable, et de montrer que ces postes offrent des opportunités d'ascension sociale. La nature des unions contractées souligne toutefois les difficultés d'intégration. Du reste, l'éloignement est pour certains une expérience douloureuse, doublée bien souvent de difficultés linguistiques finement analysées par l'auteur.

4 La troisième partie se demande comment on veille alors au salut de l'Empire. L'une des tâches principale des forces de l'ordre est de sonder l'état des esprits, de dire s'il est bon ou mauvais. Mais cet état des esprits se lit aussi dans les plaintes formulées contre la gendarmerie. Il est vrai qu'elle a fort à faire, chargée qu'elle est de lutter contre le brigandage et de veiller au bon fonctionnement de la conscription. Mais la lutte contre le brigandage rencontre, elle, les aspirations des populations. Elle conduit du reste certains gendarmes à la mort.

5 C'est néanmoins dans la quatrième partie que l'auteur se demande si l'on peut alors mourir pour l'Empire. Il revient sur le phénomène rébellionnaire pour en dresser la chronologie et montrer sa recrudescence en 1813. Il en dresse la typologie, des rébellions d'impositions aux rébellions d'explosion en passant par les rébellions de dislocation - qui éclatent quand l'Empire chancelle -, de protestation, de négociation, de conservation et de subversion. Les forces de l'ordre sont affrontées soit à des échauffourées momentanées, soit à des phénomènes insurrectionnels. La plupart des rébellions se font sans chef et sont d'ordre spontané. Elles sont de ce fait privées de tout sens politique par les autorités. L'auteur analyse enfin la dislocation de l'Empire policier.

6 Au total, il y a là un ouvrage qui offre un éclairage très précieux sur l'Empire des nouveaux Français. Il est très nourri mais on aurait aimé que la distinction entre police et gendarmerie soit mieux faite, car on passe souvent de l'une à l'autre sans distinction, avec parfois même une incursion soudaine dans le monde des gardes champêtres. Surtout le texte aurait gagné à être plus resserré : la volonté de tout dire, de tout utiliser brouille le propos et prive de forces, bien souvent, la démonstration qui manque par ailleurs de conclusions. Aurélien Lignereux, qui a déjà une belle et abondante bibliographie à son actif, n'avait pourtant pas besoin de se presser pour livrer au public le précieux fruit de cet important travail auquel il faut néanmoins rendre hommage : il est une nouvelle et belle avancée dans la connaissance du Premier Empire. Car en observant l'Empire au travers de la vie des policiers et gendarmes, 
Aurélien Lignereux donne à voir la portée et les limites de la francisation, il montre la diversité des voies d'acceptation ou de rejet de la domination française, il met en évidence les processus de construction d'un espace normatif commun. Il rappelle que l'Empire n'est décidément pas l'œuvre d'un seul homme et il ose prendre à bras-lecorps sa dimension européenne.

\section{NOTES}

1. Aurélien Lignereux, La France rébellionnaire. Les résistances à la gendarmerie (1800-1859), Rennes, Presses universitaires de Rennes, 2008.

2. Aurélien Lignereux, L’Empire des Français, 1799-1815, Paris, Le Seuil, 2012. 